\title{
Describing The Behaviours, Perception and Awareness of Bariatric Surgery Among Primary Care Physicians in Kuwait.
}

Shaimaa Alasfour ( $\nabla$ drshaimaa00@gmail.com )

Ministry of Health

Nouf Almughamis

Ministry of Health

Ahmed Ahmed

Imperial College Healthcare NHS Trust

\section{Research Article}

Keywords: bariatric surgery, obesity, physician knowledge, physician awareness, general practice

Posted Date: December 2nd, 2020

DOl: https://doi.org/10.21203/rs.3.rs-111713/v1

License: (c) (i) This work is licensed under a Creative Commons Attribution 4.0 International License.

Read Full License 


\section{Abstract}

\section{Background}

Obesity is a growing issue globally and bariatric surgery is increasingly being utilized to treat it. The prevalence of obesity in Kuwait is already high compared with global comparisons and increasing. The current study sought to assess the knowledge and attitudes of physicians in Kuwait towards obesity within their patient populations and the use of bariatric surgery.

\section{Methods}

Questionnaires were distributed to physicians across Kuwait. Responses were recorded online via Survey Monkey. The self-administered questionnaire collected data about demographic factors, knowledge of bariatric surgery, practices related to the collection of measurements related to weight and height, and attitudes towards bariatric surgery and obesity among patients.

\section{Results}

A total of 118 surveys were returned. A minority of respondents (34\%) supported the use of bariatric surgery, despite $51 \%$ having referred a patient for such a procedure. In terms of behaviours related to overweight and obesity, the majority of respondents regularly took patients weight and height, calculated $\mathrm{BMI}$, and initiated conversations about obesity when they felt they were required. Knowledge related to the morbidity and mortality experienced by those undergoing bariatric surgery was low. Among those who responded to questions related to their knowledge of mortality related to bariatric surgery, over half did not know the 30-day mortality associated with any of the procedures included within the questions.

\section{Conclusion}

Among our sample of physicians, we report a low level of support for bariatric surgery, as well as low levels of knowledge of the risks and consequences of the procedures. At the same time, while we found low levels of support for this type of surgery, over half had referred a patient for it. As obesity continues to be a key issue of public health concern, globally and within Kuwait, physician and patient education and awareness of the appropriate treatment options available becomes increasingly important.

\section{Background}

The World Health Organization estimates that approximately 1.9 billion adults are currently overweight and, within this population, 650 million are obese.(1) The Gulf States are experiencing obesity at epidemic levels,(2) with Kuwait, Qatar and Libya among the ten countries with the highest prevalence of obesity worldwide.(3) In Kuwait the prevalence of obesity has been found to be over $40 \%$,(4) with a further $37 \%$ of the population categorized as overweight; mean BMl is reported as $28.4 \mathrm{~kg} / \mathrm{m}$ - which falls at the high-end of the overweight category.(5) Within the Eastern Mediterranean Region, obesity has a significant impact upon mortality - with an estimated 417,115 deaths associated with increased BMI, 
annually, and the majority of these excess deaths are related to diabetes and cardiovascular conditions. (3)

There is an increasing body of evidence demonstrating the benefits of bariatric surgery for those who are obese, with long-term weight loss achieved consistently within this patient population following surgery.

(6) Patients who undergo bariatric surgery also experience improvements in obesity-related health outcomes - including reduced risk of morbidity and mortality from cardiovascular disease, hypertension and type-2 diabetes.(7-9) At the same time, it appears that bariatric surgery is only performed on a minority of those within the obese population, globally, and that access to such procedures differs between countries and locations.(10) In 2016, the number of bariatric surgery procedures performed globally reached 700,000 while prevalence of obesity within the population of developed countries, including the United States, has reached $\geq 30 \%$.(7,9) With obesity responsible for increasing rates of morbidity and mortality - approximately 4 million deaths globally(5) - interventions are needed that can effectively reduce its impact upon health.

Several studies have explored the awareness and use of bariatric surgery among general practitioners (GPs) in other countries, finding knowledge gaps and high rates of unmet need in terms of education about the topic. $(11,12)$ At present, there is a paucity of published information about the knowledge of health care professionals practicing in Kuwait in this regard. Given that GPs are often the first-line health care sought by patients, when seeking to gain information about their health related to overweight and obesity, the aims of the current study were to: 1) assess the knowledge and attitudes of doctors in Kuwait related to bariatric surgery and obesity among their patients and 2) explore the factors that might influence their knowledge and attitudes in this area.

\section{Methods}

The questionnaire was sent physicians across Kuwait between July-2019 and March-2020. Seventy-one questions were developed to gather demographic information (including age, gender, location), information about their professional experience (time since graduation and time in practice), behaviour related to obesity amongst their patient population (whether they took patient measurements and calculated BMI) and their knowledge and experience related to discussing obesity and bariatric surgery with their patients. The questions were adopted from the questionnaire utilized in the earlier study entitled 'Knowledge and Perception of Bariatric Surgery Among Primary Care Physicians: a Survey of Family Doctors in Ontario'.(12) In total 176 responses were received, with 118 physicians answering the majority of the questions.

All analyses were conducted using SPSS (version 27). We produced statistics to describe our physician population and then to explore their knowledge related to obesity and bariatric surgery. For continuous variables we produced frequencies, means and standard deviations, while for categorical variables our results are presented as $\mathrm{n}$ and \%. Results were calculated for the total sample, were possible, and a subset when respondents did not answer a question. 


\section{Results}

Descriptive results are given in Table One. The In total 118 respondents completed enough of the questionnaire to be included within our analysis. majority of the respondents $(81 \%)$ were women and the mean age was 37 years (SD: 9.5). Eighty-one percent of respondents indicated that they were Kuwaiti, with 16\% non-Kuwaiti Arab and 3\% non-Kuwaiti and non-Arab. The majority worked in either Kuwait City (36\%), Hawally (29\%) or Al Farwaniyah (15\%). Fifty-three percent had graduated from the Faculty of Medicine from The University of Kuwait - with a diverse range of other graduating universities including AGU, Cairo University and the Arabian Gulf University. The mean graduation year was 2007 - with approximately $70 \%$ having graduated since 2001. Mean years of experience was 9.8 (SD: 8.3). The highest level of education achieved was a Phd/DrPhD/Board Certified Program and this was reported by $42 \%$ of respondents. The majority of respondents (76\%) worked in polyclinics and centers, while $9 \%$ worked in administrative fields (including food and nutrition and public health). While $68 \%$ of respondents indicated that their specialty was Family Physician, a further $12 \%$ indicated that they were a GP. One-third of participants had $>100$ patients with $17 \%$ having between $26-50$ and $51-100$, respectively.

The sources of knowledge utilized by our sample of physicians were diverse; books were reported by $35 \%$, medical lectures by $57 \%$, the internet by $63 \%$, social media by $25 \%$, guidelines by $63 \%$ and weekly or monthly hospital/clinical seminars and lectures by $18 \%$ (Table Two). In terms of understanding the weight of their patients, the majority of physicians indicated that either they (61\%) or a nurse (53\%) took the weight of their patients; with $53 \%$ taking a patient's weight at each visit. Over $70 \%$ of respondents indicated that they knew how to measure BMI, how to calculate BMI and regularly determined BMI for each of their patients. A small minority reported that they tried to guess the BMI of their patients. Among those who did not calculate BMI time limitation was given as the main reason. Fewer indicated that they measured waist and/or hip circumference and waist-to-hip ratio. Among those who did not measure weight, responses for reasons why related to not having time, the activity not affecting their practice, not being within their role and being uncomfortable doing so.

When asked about bariatric surgery for their patients, a minority (34\%) were supportive of the procedure for patients with diabetes and a BMI $>35$, while $33 \%$ were not (Table Three). Despite this, half reported that they were comfortable initiating conversations about such procedures with their patients and would suggest surgery to patients with a BMI of $>=40$. The majority of physicians indicated that they currently had patients who had received some form of bariatric surgery; and $51 \%$ had referred a patient for such surgery. The type of bariatric surgery preferred among our physicians was laparascopic sleeve gastrectomy $(30 \%)$, followed by laparoscopic adjustable gastric band $(5 \%)-25 \%$ were unsure of their preferred surgery type. Thirty-six percent indicated that they knew who to contact in terms of gaining more information about bariatric surgery, while approximately $40 \%$ indicated that they did not know the rates of mortality and morbidity associated with different types of bariatric surgery (Table Four). Only a small number $(14 \%)$ were trained in clinical nutrition. Only $28 \%$ felt that the cost of bariatric surgery was an impediment to a patient undergoing a procedure. 


\section{Discussion}

Obesity is having an increasing impact upon the health of the global population.(13) Countries in the Middle East, including Kuwait, are experiencing epidemic levels of obesity and consequentially poorer health outcomes. $(3,5)$ Bariatric surgery is now viewed as an effective method of reducing an individual's weight/BMI, and improving health outcomes, in the long-term. $(6,8,9)$ At the same time, little is known about the experiences of obese patients and their physicians related to surgery and commentators have begun to call for more research in this area in the Middle East.(14) The current study is one of the few to explore the behaviours and knowledge of physicians working in Kuwait regarding the management of obese patients and their bariatric surgery options.

We found low levels of knowledge related to the morbidity and mortality associated with different forms of bariatric surgery. These levels are similar to those found in earlier studies from different countries, $(11,12)$ and are suggestive of the need for more education about bariatric surgery aimed at improving the knowledge of healthcare providers. At the same time, despite high levels of knowledge among patients, related to how to care for themselves post-bariatric surgery, there still appears to be unmet need related to information about bariatric surgery and a need for improved and more readily available information for all the parties involved in the decision-making process.(15) This would then enable patients and physicians the opportunity to confidently discuss their needs and aims, which in turn has the potential to improve patient adherence to post-surgery requirements and long-term outcomes.(16)

Although we found that physicians use a diverse range of information sources (including print media and the internet), we also found a lack of knowledge related to who they could call upon to receive more information about bariatric surgery. Within our sample, only $36 \%$ knew who to contact, while a 2016 study of physicians in Canada reported $42.3 \%$.(12) Both of these studies suggest the need for improved signposting for physicians so that they are able to effectively gather the information they need to support their patients in decision-making related to bariatric surgery.

We also report low levels of support for the utilization of bariatric surgery among our cohort of doctors. The reasons for this are likely diverse and could be explored in further research, perhaps using qualitative methods which would enable a deep understanding of attitudes and beliefs related to obesity and surgery. Perhaps somewhat in contradiction to this result, we found that doctors regularly recorded and calculated weight, height and $\mathrm{BMI}$, and were comfortable discussing obesity and surgery options, as well as referring patients for surgery. This appears to demonstrate that the doctors are putting aside their own personal feelings about surgery and acting in a way that is most appropriate to the needs of their patients.

Further education about the health benefits of bariatric surgery, among healthcare professionals, might encourage a more positive view of the practice. In the global context it is clear that bariatric surgery is being under-utilized within obese populations, and it could be speculated that this may partly be a result of the personal feelings and actions of physicians towards it.(17) Other reasons may relate to costs, 
patient attitudes towards it, and the communication between physician and patient. Further research is needed to fully understand why this under-utilization occurs and the factors that underpin it.

\section{Conclusion}

Within our investigation of the behaviour and knowledge related to obesity and bariatric surgery, among doctors practicing in Kuwait, we found that the majority regularly took height and weight measurements and recorded BMI. At the same time, a minority supported bariatric surgery for their patients, had a clear understanding of the mortality and morbidity related to the procedure, and knew who to contact for more information about bariatric procedures. Our study indicates that improvements in education are required to inform those at the frontline of tackling the global obesity epidemic. Further research is also necessary so that might better understand the factors related to the decision-making process that precedes bariatric surgery.

\section{Declarations}

\section{Ethics approval and consent to participate}

Informed consent was obtained from all individual participants included in the study. The Kuwait Ministry of health and the research and Ethic community Approval all methods and experimental protocols were performed accordance with the relevant guidelines and regulations (Declaration of Helsinki).

\section{Consent for publication}

Our manuscript contains no individual person's data in any form (including any individual details, images or videos).

\section{Availability of data and materials}

The datasets used and/or analysed during the current study are available from the corresponding author on reasonable request.

\section{Competing interests}

The authors have no competing interests.

\section{Funding}

Self-funded, no funding was received.

\section{Authors' contributions}

SA is responsible for literature reviews, ethical approval and the Questionnaire modification. NA is creating the Survey Monkey Questionnaires. Finally, AA supply the document for Ethical approval and 
supervise project.

All authors read and approved the final manuscript.

\section{Acknowledgements}

The authors thank Vanessa Gordon-Dseagu for her consultation to support the production of this manuscript. Also, Authors would like to thank Timothy D. Jackson and his colleagues to approve the use of the Ontario questionnaires.

\section{References}

1. Obesity and overweight [Internet]. [cited 2020 Oct 9]. Available from: https://www.who.int/newsroom/fact-sheets/detail/obesity-and-overweight

2. Balhareth A, Meertens R, Kremers S, Sleddens E. Overweight and obesity among adults in the $\mathrm{G}$ ulf $\mathrm{S}$ tates: A systematic literature review of correlates of weight, weight-related behaviours, and interventions. Obes Rev. 2019 May;20(5):763-93.

3. GBD 2015 Eastern Mediterranean Region Obesity Collaborators. Burden of obesity in the Eastern Mediterranean Region: findings from the Global Burden of Disease 2015 study. Int J Public Health. 2018 May;63(S1):165-76.

4. AlKhaldi LK, AlSaffar NA, AlHamdan F, Almutairi R, Alipour MH, Al Haddad E, et al. Long-term outcomes after laparoscopic sleeve gastrectomy in Kuwait. Ann Saudi Med. 2019 Mar;39(2):100-3.

5. Weiderpass E, Botteri E, Longenecker JC, Alkandari A, Al-Wotayan R, Al Duwairi Q, et al. The Prevalence of Overweight and Obesity in an Adult Kuwaiti Population in 2014. Front Endocrinol. 2019 Jul 9;10:449.

6. Maciejewski ML, Arterburn DE, Van Scoyoc L, Smith VA, Yancy WS, Weidenbacher HJ, et al. Bariatric Surgery and Long-term Durability of Weight Loss. JAMA Surg. 2016 Nov 1;151(11):1046.

7. Gero D, Raptis DA, Vleeschouwers W, van Veldhuisen SL, Martin AS, Xiao Y, et al. Defining Global Benchmarks in Bariatric Surgery: A Retrospective Multicenter Analysis of Minimally Invasive Roux-enY Gastric Bypass and Sleeve Gastrectomy. Ann Surg. 2019 Nov;270(5):859-67.

8. Koliaki C, Liatis S, le Roux CW, Kokkinos A. The role of bariatric surgery to treat diabetes: current challenges and perspectives. BMC Endocr Disord [Internet]. 2017 Aug 10 [cited 2020 Oct 9];17. Available from: https://www.ncbi.nlm.nih.gov/pmc/articles/PMC5553790/

9. Kuno T, Tanimoto E, Morita S, Shimada YJ. Effects of Bariatric Surgery on Cardiovascular Disease: A Concise Update of Recent Advances. Front Cardiovasc Med. 2019 Jul 10;6:94.

10. Welbourn R, Hollyman M, Kinsman R, Dixon J, Liem R, Ottosson J, et al. Bariatric Surgery Worldwide: Baseline Demographic Description and One-Year Outcomes from the Fourth IFSO Global Registry Report 2018. Obes Surg. 2019 Mar;29(3):782-95. 
11. Zacharoulis D, Bakalis V, Zachari E, Sioka E, Tsimpida D, Magouliotis D, et al. Current knowledge and perception of bariatric surgery among Greek doctors living in Thessaly: Current knowledge of bariatric surgery. Asian J Endosc Surg. 2018 May;11(2):138-45.

12. Auspitz M, Cleghorn MC, Azin A, Sockalingam S, Quereshy FA, Okrainec A, et al. Knowledge and Perception of Bariatric Surgery Among Primary Care Physicians: a Survey of Family Doctors in Ontario. Obes Surg. 2016 Sep;26(9):2022-8.

13. GBD 2015 Obesity Collaborators, Afshin A, Forouzanfar MH, Reitsma MB, Sur P, Estep K, et al. Health Effects of Overweight and Obesity in 195 Countries over 25 Years. N Engl J Med. 2017 06;377(1):1327.

14. AlMarri F, Al Sabah S, Al Haddad E, Vaz JD. A Call for More Research from the Arabian Gulf. Obes Surg. 2017 Aug;27(8):2034-43.

15. Alia S, Ali HI, Zoubeidi T, Ahmed M. Nutrition Knowledge and Satisfaction Levels of Postbariatric Surgery Adults in the United Arab Emirates: A Pilot Study. J Nutr Metab. 2019 Apr 1;2019:1-7.

16. Sobhani Z, Amini M, Zarnaghash M, Hosseini SV, Foroutan HR. Self-Management Behaviors in Obese Patients Undergoing Surgery Based on General and Specific Adherence Scales. World J Plast Surg. 2019 Jan;8(1):85-92.

17. Gasoyan H, Tajeu G, Halpern MT, Sarwer DB. Reasons for underutilization of bariatric surgery: The role of insurance benefit design. Surg Obes Relat Dis. 2019 Jan;15(1):146-51.

\section{Tables}




\begin{tabular}{|c|c|}
\hline \multicolumn{2}{|l|}{ Table One: Descriptive Results } \\
\hline & Total $(n=118)$ \\
\hline Age (mean, SD) & $36.7(9.5)$ \\
\hline \multicolumn{2}{|l|}{ Gender } \\
\hline Male $(n, \%)$ & $21(18)$ \\
\hline Female & $95(81)$ \\
\hline \multicolumn{2}{|l|}{ Nationality } \\
\hline Kuwaiti & $95(81)$ \\
\hline Non-Kuwaiti Arab & $19(16)$ \\
\hline Non-Kuwaiti, non-Arab & $4(3)$ \\
\hline \multicolumn{2}{|l|}{ Location } \\
\hline Kuwait City & $43(36)$ \\
\hline Hawally & $34(29)$ \\
\hline Al Farwanjyah & $18(15)$ \\
\hline Al Ahmedi & $6(5)$ \\
\hline Al Jahre & $5(4)$ \\
\hline Mubarak Alkabeer & $10(9)$ \\
\hline \multicolumn{2}{|l|}{ Graduated Institution } \\
\hline University of Kuwait & $62(53)$ \\
\hline Other & $55(47)$ \\
\hline Year of Graduation (mean, SD) & $2007(9.2)$ \\
\hline \multicolumn{2}{|l|}{ Highest Qualification } \\
\hline BSc in Medicine & $33(28)$ \\
\hline Higher Diploma Degree & $15(13)$ \\
\hline $\mathrm{MSc} / \mathrm{MPh} / 1^{\text {st }}$ part of Board Examination & $25(21)$ \\
\hline PhD/DrPhD/Board Certified Program & $49(42)$ \\
\hline Other & $12(10)$ \\
\hline \multicolumn{2}{|l|}{ Specialty } \\
\hline GP & 14 (12) \\
\hline
\end{tabular}




\begin{tabular}{|ll|}
\hline Family Physician & $80(68)$ \\
\hline Medical Specialties & $6(5)$ \\
\hline Other & $2(2)$ \\
\hline Location of Work & $6(5)$ \\
\hline Polyclinic and Centers & \\
\hline Administrative Fields & $90(76)$ \\
\hline Patient Load & $11(9.3)$ \\
\hline$<25$ & \\
\hline $26-50$ & $16(14)$ \\
\hline $51-100$ & $26(22)$ \\
\hline$>100$ & $23(19)$ \\
\hline
\end{tabular}




\begin{tabular}{|ll|}
\hline Table Two: Knowledge and Behavior & \\
\hline & Total \\
\hline Sources of Knowledge & \\
\hline Available Books & $41(35)$ \\
\hline Medical Lectures & $67(57)$ \\
\hline Internet & $74(63)$ \\
\hline Social Media & $30(25)$ \\
\hline Guidelines & $74(63)$ \\
\hline Weekly/Monthly Hospital/Clinic Lectures & $21(18)$ \\
\hline Do you weigh your patients? & \\
\hline Doctor & $72(61)$ \\
\hline Nurse & $63(53)$ \\
\hline Do you take your patients height? & \\
\hline Doctor & $62(53)$ \\
\hline Nurse & $69(59)$ \\
\hline How regularly to you measure weight? & \\
\hline Each visit & $63(53)$ \\
\hline Each year & $20(17)$ \\
\hline Never & $9(8)$ \\
\hline Do you know how to measure BMl? & \\
\hline Yes & $67)$ \\
\hline Do you calculate the BMl of your patients? & \\
\hline Yes & \\
\hline Do you initiate conversations about obesity? & \\
\hline Yes & \\
\hline
\end{tabular}


Table Three: Bariatric Surgery Related Variables

Do you support bariatric surgery for obese patients?

Yes

$40(34)$

Have you ever referred your patients for bariatric surgery?

Yes

Minimum BMI for bariatric surgery?

30

35

$22(19)$

40

$50(42)$

45

5 (4)

$>50$

$3(3)$

What is your preferred bariatric surgery?

Laparoscopic sleeve gastrectomy $35(30)$

Laparoscopic adjustable gastric band

Roux-en-Y

5 (4)

Not sure $30(25)$

Other

Number of bariatric surgery patients

0

$1-5$

$13(11)$

6-10

$14(12)$

$11-15$

16 (14)

$16-20$

7 (6)

$>20$

23 (19)

Do you know who to contact about bariatric surgery?

Yes

Are you trained in clinical nutrition?

Do you think there is a cost barrier to surgery?

Yes 


\begin{tabular}{|c|c|}
\hline \multicolumn{2}{|c|}{ Table Four: Knowledge of Mortality and Morbidity* } \\
\hline Estimate & Response \\
\hline Roux-En-Y & $(n=78)$ \\
\hline$<0.1$ & 9 \\
\hline $0.1-0.2$ & 9 \\
\hline $0.3-1.0$ & 11 \\
\hline $1.1-2.0$ & 2 \\
\hline $2.1-4.0$ & 3 \\
\hline$>4.0$ & 2 \\
\hline Don’t Know & 42 \\
\hline \multicolumn{2}{|c|}{ Laparascopic } \\
\hline$<0.1$ & 18 \\
\hline $0.1-0.2$ & 11 \\
\hline $0.3-1.0$ & 5 \\
\hline $1.1-2.0$ & 1 \\
\hline $2.1-4.0$ & 1 \\
\hline$>4.0$ & 2 \\
\hline Don't Know & 40 \\
\hline \multicolumn{2}{|c|}{ Adjustable Band } \\
\hline$<0.1$ & 22 \\
\hline $0.1-0.2$ & 3 \\
\hline $0.3-1.0$ & 1 \\
\hline $1.1-2.0$ & 1 \\
\hline $2.1-4.0$ & 3 \\
\hline$>4.0$ & 2 \\
\hline Don't Know & 46 \\
\hline
\end{tabular}

*Thirty-day mortality for each of the following procedures is $<0.1$. 


\section{Supplementary Files}

This is a list of supplementary files associated with this preprint. Click to download.

- QperceptionandAwarenessofBariatricSurgeryAmongKuwaitiPhysiciansSAMOH.pdf 